Case report

\title{
Herpes simplex virus bullous keratitis misdiagnosed as a case of pseudophakic bullous keratopathy with secondary glaucoma: an unusual presentation Sreedharan Athmanathan*1, Mittanamalli S Sridhar², Raj Anand ${ }^{2}$, Anil K Mandal ${ }^{3}$ and Gullapalli N Rao ${ }^{2}$
}

\author{
Address: ${ }^{1}$ Jhaveri Microbiology Center, Hyderabad Eye Research Foundation, LV Prasad Eye Institute, Hyderabad, India, ${ }^{2}$ Cornea services, LV \\ Prasad Eye Institute, Hyderabad, India and ${ }^{3}$ VST Center for Glaucoma Care L.V.Prasad Eye Institute, Hyderabad, India \\ E-mail: Sreedharan Athmanathan* - sreedhar@lvpeye.stph.net; Anil K Mandal - mandal@lvpeye.stph.net; \\ Gullapalli N Rao - gnrao@lvpeye.stph.net \\ ${ }^{*}$ Corresponding author
}

This article is available from: http://www.biomedcentral.com/I47I-24I5/I/2

(c) 200I Athmanathan et al, licensee BioMed Central Ltd.

\begin{abstract}
Purpose: To report an unusual case of herpetic bullous keratitis misdiagnosed as a case of pseudophakic bullous keratopathy with secondary glaucoma.

Results: A retrospective analysis of the case record of a 60-year-old man who had earlier undergone bilateral cataract surgery, was done. He presented with a complaint of decrease in vision in the right eye of 20 days duration. On examination, cornea showed epithelial bullae all over the surface with stromal and epithelial edema. Intraocular pressure was $30 \mathrm{~mm}$ of $\mathrm{Hg}$ in RE. He was treated with anti-glaucoma medications. Two dendritic lesions were seen in the cornea during a subsequent visit four days later. Virological investigations confirmed a diagnosis of Herpes simplex keratitis. He was treated with topical acyclovir.
\end{abstract}

Conclusions: This case highlights the fact that herpes simplex keratitis can present initially as a more diffuse corneal stromal and epithelial edema with epithelial bullae mimicking bullous keratopathy. Herpetic bullous keratitis, although unusual, should be considered in the differential diagnosis under such circumstances.

\section{Introduction}

Herpes simplex keratitis (HSK) is a sight threatening ocular infection and is a leading cause of corneal blindness [1]. Clinical presentation of HSK is often protean. While a typical and common presentation of HSK is usually a dendritic or geographic ulcer, atypical presentations are not uncommon [2]. We report here an unusual presentation of HSK. The patient presented to us with bullous keratitis, which was misdiagnosed as a case of pseudophakic bullous keratopathy (PBK) with secondary glaucoma.

\section{Case Report}

A sixty-year-old male presented to our cornea services with a complaint of progressive diminution of vision, in the right eye, of 20 days duration. There were no other ocular or systemic complaints. He gave a history of having undergone extracapsular cataract extraction with 


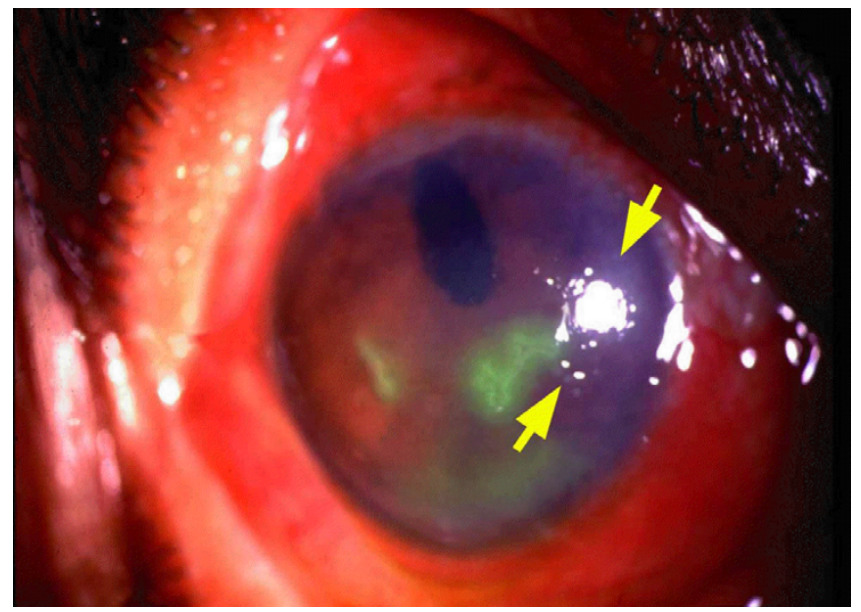

Figure I

Diffuse illumination of the RE: Diffuse illumination of the right eye showing two dendritic lesions stained by fluorescein, multiple bullae (arrows) and a diffuse corneal edema.

posterior chamber intraocular lens implantation 4.5 years earlier in the RE and phacoemulsification with posterior chamber intraocular lens implantation 2 years earlier in the LE. Surgery and postoperative period were uneventful on both occasions with a final visual acuity of $6 / 6$ in both eyes. On examination, visual acuity in RE was restricted to perception of light with accurate projection of light in all the four quadrants. Conjunctiva was congested and cornea showed epithelial bullae all over the surface with mild to moderate epithelial and stromal edema. Anterior chamber was deep and quiet. Intraocular lens was in place and fundus details were within normal limits. Intraocular pressure in the RE was $30 \mathrm{~mm}$ of $\mathrm{Hg}$ and LE was $14 \mathrm{~mm} \mathrm{Hg}$. A diagnosis of PBK with secondary glaucoma, was made. Patient was immediately treated with intravenous mannitol (350 cc) and a single oral dose of $250 \mathrm{mg}$ acetazolamide, followed by $250 \mathrm{mg}$ three times daily and $0.5 \%$ timolol eye drops twice daily for the right eye. Intraocular pressure was $16 \mathrm{~mm}$ of $\mathrm{Hg}$ following mannitol administration and he was discharged. Patient presented to us four days later. Visual acuity in the RE had improved to counting fingers at $1 \mathrm{~m}$ and 6/6 in LE. On examination, cornea showed few epithelial bullae with mild to moderate epithelial and stromal edema. The intraocular pressure in the right eye was $16 \mathrm{~mm} \mathrm{Hg}$. Two dendritic lesions were seen (Figure 1) in the cornea. A clinical diagnosis of PBK with HSK was made. Corneal scrapings were collected for virological investigations. The patient was treated with $3 \%$ acyclovir eye ointment five times daily and cyclopentolate eye drops twice daily for the RE. The patient was lost to follow up.
Papanicolaou stained smear of the corneal scraping showed multinucleated giant cells and intranuclear eosinophilic inclusion (Figure 2). HSV-1 antigen was detected in the epithelial cells of the corneal scraping and the smear revealed multinucleated giant cells (Figure 3). HSV-1 was isolated in culture and PCR was positive for HSV DNA using primers, which amplified a 179 bp region of the DNA polymerase gene of HSV 1/2.

\section{Discussion}

This case was initially diagnosed as PBK with secondary glaucoma based on a history of cataract surgery, presence of diffuse corneal stromal and epithelial edema, epithelial bullae and a raised intraocular pressure in the affected eye. The subsequent appearance of typical dendritic lesions and virological investigations confirmed a diagnosis of herpetic bullous keratitis. Further, the present event occurred after 4 years after the cataract surgery. Since corneal latency of HSV has been described [4], it is perfectly reasonable to assume that herpes rather than the previous endothelial damage caused the whole syndrome.

The presence of glaucoma possibly suggests HSV trabeculitis in the affected eye. It is difficult to ascertain this finding since we did not perform any investigation. A PCR assay for the detection of HSV DNA using aqueous humor would have provided supporting evidence.

This event was possibly a syndrome of HSV stromal and epithelial keratitis with trabeculitis, which explains the signs of a diffuse corneal stromal and epithelial edema

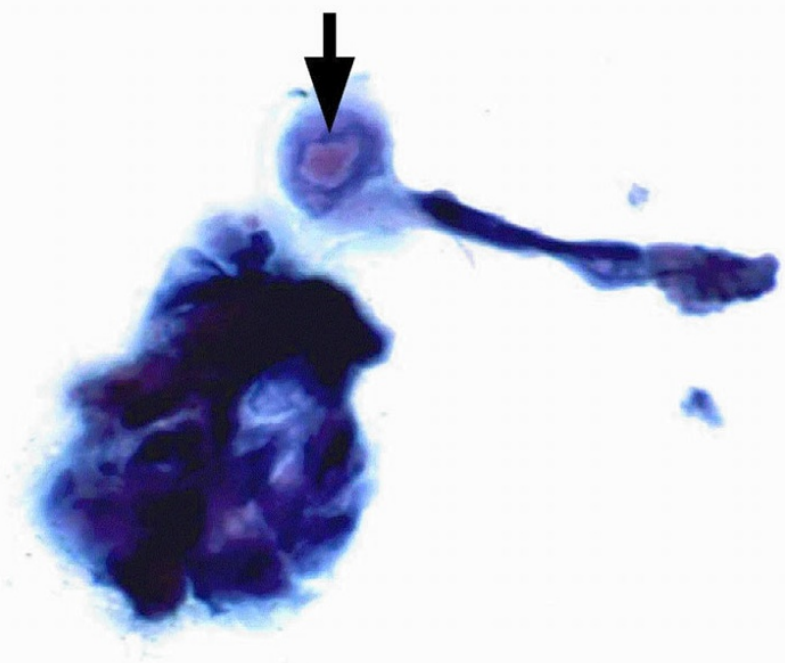

Figure 2

Papanicolaou stain of the corneal scraping: Corneal scraping showing intranuclear eosinophilic inclusion (arrow) in an epithelial cell $(\times 500)$. 

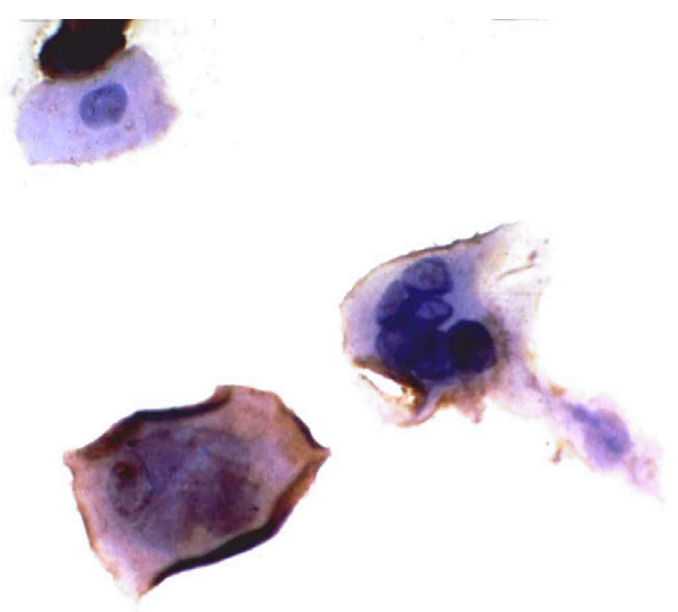

Figure 3

Immunoperoxidase assay of the corneal scraping: Corneal scraping showing multinucleated giant cells and the presence of HSV-I antigen (Seen as brown precipitate) $(\times$ 500).

and an acute rise in the intraocular pressure in the affected eye. The formation of epithelial bullae due to corneal edema could have predisposed the cornea for the development of dendritic ulcers. It has earlier been shown that the presence of corneal epithelial bullae has a statistically significant effect on the rate of ulcer development [3].

This case highlights the fact that HSK can present initially as a more diffuse corneal stromal and epithelial edema with epithelial bullae mimicking bullous keratopathy.

To the best of our knowledge and based on a MEDLINE search, such a presentation of HSK has not been documented.

Herpetic bullous keratitis, although unusual, should be considered in the differential diagnosis under such circumstances to prevent further complications and for the prompt institution of specific antiviral therapy.

\section{Declaration of competing interests}

None declared

\section{Acknowledgement}

We thank the patient for giving us informed consent to publish the details of the case.

\section{References}

I. Yamamoto S, Shimomura Y, Kinoshita S, Nishida K, Yamamoto R, Tano $Y$ : Detection of herpes simplex virus DNA in human tear film by polymerase chain reaction Am J Ophthalmol 1994, II7:160-163

2. Koizumi N, Nishida K, Adachi W, Tei M, Honma Y, Dota A, Sotozono C, Yokoi N, Yamamoto S, Kinoshita S: Detection of herpes simplex virus DNA in atypical epithelial keratitis using polymerase chain reaction $\mathrm{Br}$ J Ophthalmol 1999, 83:957-960
3. Luchs JI, Cohen EJ, Rapuano CJ, Laibson PR: Ulcerative keratitis in bullous keratopathy Ophthalmology 1997, 104:816-822

4. Rong BL, Pavan-Langston D, Weng QP, Martinez R, Cherry JM, Dunkel EC: Detection of herpes simplex virus thymidine kinase and latency-associated transcript gene sequences in human herpetic corneas by polymerase chain reaction amplification Invest Ophthalmol Vis Sci 1991, 32:1808-1815
Publish with BioMedcentral and every
scientist can read your work free of charge

"BioMedcentral will be the most significant development for disseminating the results of biomedical research in our lifetime." Paul Nurse, Director-General, Imperial Cancer Research Fund

Publish with BMC and your research papers will be:

- available free of charge to the entire biomedical community

- peer reviewed and published immediately upon acceptance

- cited in PubMed and archived on PubMed Central

- yours - you keep the copyright

Submit your manuscript here:

http://www.biomedcentral.com/manuscript/
BioMedcentral.com editorial@biomedcentral.com 